\title{
Erythrocyte membrane fatty acids and breast cancer risk by tumor tissue expression of immuno-inflammatory markers and fatty acid synthase: a nested case-control study
}

Emma E. McGee ${ }^{1,2^{*}}$ D, Claire H. Kim ${ }^{1,2}$, Molin Wang ${ }^{1,2,3}$, Donna Spiegelman ${ }^{4,5}$, Daniel G. Stover ${ }^{6}$, Yujing J. Heng ${ }^{7}$, Laura C. Collins ${ }^{7}$, Gabrielle M. Baker ${ }^{7}$, Maryam S. Farvid ${ }^{2}$, Pepper Schedin ${ }^{8}$, Sonali Jindal ${ }^{8}$, Rulla M. Tamimi ${ }^{1,2,9}$ and A. Heather Eliassen ${ }^{1,2}$

\begin{abstract}
Background: Previous studies of fatty acids and breast cancer risk have shown mixed results, which may be due in part to tumor heterogeneity. Prior research has also illustrated an important role of specific fatty acids in immune regulation, $T$ cell function, and inflammation, indicating that the effects of specific fatty acids on breast cancer risk may vary by tumor expression of immuno-inflammatory markers. We therefore aimed to evaluate the relationships between prediagnostic erythrocyte membrane fatty acids and breast cancer risk by tumor tissue expression of immuno-inflammatory markers (CD4, CD8, CD20, CD163, COX-2) and fatty acid synthase (FAS).

Methods: We conducted a matched case-control study nested within the Nurses' Health Study II ( $n=235$ cases and 235 controls). Blood samples were collected from 1996 to 1999. Tumor tissue blocks were collected for cases diagnosed after blood collection and through 2006. Unconditional nominal polytomous logistic regression adjusted for matching factors and potential confounders was used to assess whether associations between fatty acids and breast cancer risk varied by tumor expression subtype, ascertained via immunohistochemistry. Odds ratios (OR) and 95\% confidence intervals (Cl) were estimated separately by tumor expression subtype using unconditional logistic regression.

(Continued on next page)
\end{abstract}

\footnotetext{
* Correspondence: emcgee@hsph.harvard.edu

${ }^{1}$ Channing Division of Network Medicine, Department of Medicine, Brigham and Women's Hospital and Harvard Medical School, Boston, MA, USA ${ }^{2}$ Department of Epidemiology, Harvard T.H. Chan School of Public Health, Boston, MA, USA

Full list of author information is available at the end of the article
}

(c) The Author(s). 2020 Open Access This article is licensed under a Creative Commons Attribution 4.0 International License, which permits use, sharing, adaptation, distribution and reproduction in any medium or format, as long as you give appropriate credit to the original author(s) and the source, provide a link to the Creative Commons licence, and indicate if changes were made. The images or other third party material in this article are included in the article's Creative Commons licence, unless indicated otherwise in a credit line to the material. If material is not included in the article's Creative Commons licence and your intended use is not permitted by statutory regulation or exceeds the permitted use, you will need to obtain permission directly from the copyright holder. To view a copy of this licence, visit http://creativecommons.org/licenses/by/4.0/ The Creative Commons Public Domain Dedication waiver (http://creativecommons.org/publicdomain/zero/1.0/) applies to the data made available in this article, unless otherwise stated in a credit line to the data. 
(Continued from previous page)

Results: Associations between fatty acids and breast cancer risk did not vary substantially by tumor CD4, CD20, CD163, or COX-2. However, n-3 polyunsaturated fatty acids (PUFAs) were inversely associated with CD8 ${ }^{\text {low }}$ but not CD $8^{\text {high }}$ cancers $\left(C D 8^{\text {low }} \mathrm{OR}_{\mathrm{T} 3}\right.$ vs $\mathrm{T} 1=0.45,95 \% \mathrm{Cl} 0.23-0.87, P_{\text {trend }}=0.02 ; \mathrm{CD}^{\text {high }} \mathrm{OR}_{\mathrm{T} 3 \text { vs } \mathrm{T} 1}=1.19,95 \% \mathrm{Cl} 0.62-2.26$, $\left.P_{\text {trend }}=0.62 ; P_{\text {het }}=0.04\right)$. n-6 PUFAs were suggestively inversely associated with $C D 8^{\text {high }}$ but not CD ${ }^{\text {low }}$ cancers $\left(\mathrm{CD}^{\text {high }} \mathrm{OR}_{\mathrm{T} 3}\right.$ vs $\mathrm{T} 1=0.61,95 \% \mathrm{Cl} 0.32-1.14, P_{\text {trend }}=0.11 ; \mathrm{CD}^{\text {low }} \mathrm{OR}_{\mathrm{T} 3}$ vs $\mathrm{T} 1=1.63,95 \% \mathrm{Cl} 0.87-3.04, P_{\text {trend }}=0.12 ;$ $\left.P_{\text {het }}=0.02\right)$. Trans fatty acids were positively associated with FAS ${ }^{\text {high }}$ but not FAS ${ }^{\text {low }}$ tumors $\left(F A S^{\text {high }} \mathrm{OR}_{\mathrm{T} 3}\right.$ vs $\mathrm{T1}=2.94$, 95\% Cl 1.46-5.91, $P_{\text {trend }}=0.002 ;$ FAS $^{\text {low }} \mathrm{ORT}_{\mathrm{T} 3}$ vs T1 $\left.=0.99,95 \% \mathrm{Cl} 0.52-1.92, P_{\text {trend }}=0.97 ; P_{\text {het }}=0.01\right)$.

Conclusion: Results indicate that the effects of n-3 PUFAs, n-6 PUFAs, and trans fatty acids on breast cancer risk may vary by tumor tissue expression subtypes. Findings suggest potential immuno-modulatory and FAS-mediated mechanisms.

Keywords: Breast cancer, Erythrocyte membrane, Fatty acid, Immune marker, Inflammation, Tumor-infiltrating lymphocytes, Fatty acid synthase, COX-2

\section{Background}

Growing experimental evidence indicates that some fatty acids may influence breast cancer risk through a variety of immuno-inflammatory mechanisms. For example, marine-derived $\mathrm{n}-3$ polyunsaturated fatty acids (PUFAs) have numerous anti-inflammatory effects [1] which may reduce breast cancer risk [2], while trans fatty acids may increase breast cancer risk through proinflammatory mechanism [3-6]. Endogenously synthesized fatty acids may also impact cancer risk, as most tumors are highly dependent on de novo fatty acid synthesis for cellular proliferation [7, 8]. However, the epidemiologic evidence for an effect of circulating fatty acids on breast cancer risk remains inconclusive [9-22]. Relatively few prior studies have assessed associations with erythrocyte membrane fatty acids [17-22], which are indicative of both dietary fat intake over several months [23] and endogenous fatty acid synthesis and transformation. Importantly, the effects of fatty acids on breast cancer risk may differ not only by type of fatty acid but also by breast tumor expression subtype, underscoring the importance of further characterizing associations by tumor subtype.

In a recent analysis within the Nurses' Health Study II (NHSII), we found that some prediagnostic erythrocyte membrane fatty acids, including several trans fatty acids, saturated fatty acids, dairy-derived fatty acids, and n-3 PUFAs, were associated with breast cancer risk among obese/overweight women, but not among women overall [17]. These data suggest that specific fatty acids may have stronger effects on breast cancer risk in a state of chronic inflammation, such as in overweight/obesity. In fact, extensive research has illustrated a multifaceted role of specific fatty acids in immune regulation, $T$ cell function, and inflammation $[1,24-26]$, indicating that the relationships between fatty acids and breast cancer risk may also vary by tumor expression of immunoinflammatory markers.
The immune cells in the tumor microenvironment play an important role in neoplastic evolution and can drive either antitumor or protumor activities [27]. For example, in breast cancer, tumor infiltration by cytotoxic $\mathrm{CD} 8+\mathrm{T}$ cells has been associated with improved disease-free and breast cancer-specific survival, particularly in triple-negative tumors [28], while CD4+ T helper lymphocytes may have either tumor-promoting or tumor-inhibiting properties depending on their cytokine expression profiles and the tumor microenvironment [29]. Although they are less well-studied, CD20+ B cells, which play an integral role in humoral immunity and shape the functions of other immune cells, and CD163+ cells, a marker of anti-inflammatory M2 macrophages [30], may also have prognostic value in breast cancer [31-34]. In addition, breast tumor tissue overexpression of cyclooxygenase-2 (COX-2), a key enzyme in fatty acid metabolism and prostaglandin production, has been associated with markers of poor prognosis [35], while fatty acid synthase (FAS), a multi-enzyme complex that regulates de novo fatty acid synthesis, can provide proliferative and metastatic capacity to cancer cells and is also commonly overexpressed in breast cancer [36]. Notably, experimental evidence indicates that the expression of each of these tumor markers may be influenced by fatty acid metabolism [24-26, 36].

Thus, we hypothesized that the relationships between specific fatty acids and breast cancer risk may vary by tumor tissue expression subtypes and that the effects of anti-inflammatory fatty acids may only be observed in a subset of tumors with inflammatory expression profiles. Characterization of this potential heterogeneity by breast tumor expression subtype could provide mechanistic insight into the roles of fatty acids in breast cancer risk, particularly with regard to inflammation and the immune response. We therefore aimed to prospectively investigate the relationships between erythrocyte membrane fatty acid concentrations and subsequent 
breast cancer risk by tumor tissue expression of several immuno-inflammatory markers (CD4, CD8, CD20, CD163, COX-2) and FAS.

\section{Methods}

\section{Design and study population}

We conducted a nested case-control study within NHSII, an ongoing, prospective cohort study initiated in 1989. At baseline, a total of 116,429 female registered nurses aged 25 to 42 years residing in 14 US states were recruited. Since then, women have been followed biennially via questionnaires. From 1996 to 1999, a subset of NHSII study participants $(n=29,611)$ who were cancer-free and aged 32 to 54 years provided blood samples. Details of the blood collection procedures have been described previously [37]. Briefly, samples were drawn and shipped on ice via overnight courier to the study's central laboratory where they were aliquoted into plasma, white blood cells, and red blood cells. All samples have since been stored in continuously monitored liquid nitrogen freezers at $\leq-130^{\circ} \mathrm{C}$. As of 2009 , followup of the blood cohort was $94.5 \%$ [38].

This study protocol was approved by the institutional review boards of the Brigham and Women's Hospital, Harvard T.H. Chan School of Public Health, and participating registries, as required. All study participants provided written informed consent.

\section{Case and control selection}

Cases $(n=235)$ were participants who were diagnosed with breast cancer after blood collection but before the end of 2006 and for whom both erythrocyte fatty acid and tumor tissue data were available. Breast cancer diagnoses were self-reported by participants on biennial questionnaires or identified through death records. With consent from participants or next of kin, medical records were reviewed by study physicians blinded to exposure status in order to confirm diagnoses and ascertain additional clinical information. All breast cancer cases included in this analysis were confirmed via medical record review.

Controls $(n=235)$ were selected via risk-set sampling and individually matched to cases on case diagnosis date, age at blood collection ( \pm 2 years), menopausal status at blood collection and in the questionnaire cycle before cancer diagnosis/control index date (premenopausal, postmenopausal, unknown), self-reported race/ethnicity (white, non-white), fasting status at blood collection $(<2$, $2-4,5-7,8-11, \geq 12 \mathrm{~h}$ since last meal), and month ( \pm 1 month) and time of day $( \pm 2 \mathrm{~h})$ of blood collection. Women who were premenopausal at blood collection and provided samples timed in the menstrual cycle [39] were further matched on luteal day ( \pm 1 day). Postmenopausal women were additionally matched on menopausal hormone therapy use at blood collection (yes, no).

\section{Tumor tissue ascertainment}

We requested formalin-fixed paraffin-embedded tissue samples from hospitals throughout the USA where women underwent primary breast tumor resection. Tissue samples were obtained from approximately $60 \%$ of confirmed breast cancer cases reported through 2006, and similar age-adjusted distributions of reproductive factors were observed for cases with vs. without tissue blocks [40]. Tumor microarrays (TMAs) were constructed at the Dana Farber Harvard Cancer Center Tissue Microarray Core Facility, Boston, MA. As described previously [41], TMAs were assembled by taking three 0.6-mm-diameter cores from each breast cancer sample and inserting cores into a recipient TMA block.

\section{Tumor tissue analyses}

Immunohistochemistry was conducted on $5-\mu \mathrm{m}$ paraffin sections of TMA blocks. The panel of immunohistochemical markers included four tumor-infiltrating immune cells representing a range of biological functions (CD4, CD8, CD20, CD163), COX-2, and FAS. Cores with fewer than 100 cells were excluded from all analyses due to lack of sufficient tissue. Cases included in the present study had on average 2.4 to 2.6 cores available for analysis across markers. Staining positivity for all markers except COX-2 was determined using an automated computational image analysis system (Definiens Tissue Studio Software, Munich, Germany). Positivity was defined for each individual marker as the mean percentage of cells staining positive, which was calculated by dividing the sum of the number of cells staining positive across all cores by the sum of the total cell count across cores. Positivity was reported separately for epithelial and stromal cell compartments. In primary analyses of the four tumor-infiltrating immune cells, we evaluated positivity in stromal cells on the basis of recommendations from an International Tumor-Infiltrating Lymphocytes (TILs) Working Group [42] and findings from Medrek et al. [34]. In secondary analyses, we evaluated positivity in epithelial cells and in epithelial and stromal cells combined. For FAS, positivity was minimal in stromal cells (median 2.1\%) compared with epithelial cells (median $84.2 \%$ ); therefore, we only evaluated epithelial cell positivity.

Tumor-infiltrating immune cells and FAS were also assessed manually by a pathologist (GMB) for comparison to the automated computational analysis (Additional file 1: Supplemental Methods). Agreement between automated and manual assessment was evaluated using Spearman correlation coefficients. 
The expression of COX-2 in breast tumor epithelial cells [43-45] was assessed in Dr. Pepper Schedin's laboratory (Oregon Health and Science University, Portland, OR, USA). Based on previous reports of differing COX-2 staining patterns for the monoclonal antibodies produced by Cayman Chemical (CX229 clone, Ann Arbor, MI, USA; RRID:AB_10078980) and Thermo Fisher Scientific (SP21 clone, Waltham, MA, USA; RRID:AB_10984436) [46], TMA slides were dual-stained at a single time point using both antibodies and labeled with distinct chromogens so that the two COX-2 signals could be distinguished. COX-2 staining results were analyzed using the Aperio co-localization image analysis algorithm and expressed as percentages of positively stained area for each antibody. In primary analyses, we examined the mean percentage area across all three cores that stained positive for at least one of the two antibodies. In supplemental analyses, we examined the mean percentage area for each antibody separately.

For each marker, tumor expression subtype was defined as either low ( $<$ median percent positivity among all cases) or high ( $\geq$ median percent positivity among all cases). On the basis of prior literature [47], we also classified tumors according to their CD4/CD8 ratio as either CD4/CD8 low (< median among all cases) or CD4/CD8 high ( $\geq$ median among all cases).

\section{Fatty acid ascertainment}

Details of the erythrocyte membrane fatty acid measurements, nomenclature, and groupings have been described previously (Additional file 1: Supplemental Methods) [17]. Briefly, 34 individual erythrocyte membrane fatty acids measured using gas-liquid chromatography [48] were evaluated as percentages of total fatty acids. In primary analyses, we assessed five fatty acid groups: total saturated fatty acids (SFA), monounsaturated fatty acids (MUFA), n-3 polyunsaturated fatty acids (PUFAs), n-6 PUFA, and trans fatty acids (TFA). Coefficients of variation (CVs) for these groups ranged from 3.3 to $9.1 \%$, with the exception of trans fatty acids which had a $\mathrm{CV}$ of $37.7 \%$.

In secondary analyses, we examined associations with individual fatty acids and the ratio of total n-6/n-3 PUFA [49]. We also analyzed the saturation indices $\mathrm{SI}_{\mathrm{n}-7}$ (palmitic/palmitoleic acid) and $\mathrm{SI}_{\mathrm{n}-9}$ (stearic/oleic acid) as indicators of stearoyl-CoA desaturase activity, a key enzyme in the biosynthesis of MUFA from SFA [50, 51]. Finally, we examined dairy-derived fatty acids (SFA and TFA primarily from milk or meat from cattle or other ruminants, including pentadecanoic acid, margaric acid, and palmitelaidic acid) and industrial trans fatty acids (TFA derived from partially hydrogenated oils, including 18:1 trans and 18:2 trans).

\section{Statistical analyses}

Descriptive statistics were used to summarize the distributions of cases and controls by demographic and epidemiologic characteristics. Spearman correlations were used to assess associations between immune marker expression levels (percent positivity) within the same tumor cell compartment and between cell compartments. Intraclass correlation coefficients (ICCs) were calculated for each tumor marker (as measured in primary analyses) across cores from the same participant. We also evaluated associations between tumor marker expression levels and other tumor characteristics measured at diagnosis, including estrogen receptor (ER) status $(\mathrm{ER}+, \mathrm{ER}-)$, progesterone receptor $(\mathrm{PR})$ status $(\mathrm{PR}+$, PR-), human epidermal growth factor receptor 2 (HER2) status (HER2+, HER2-), tumor grade (I, II, III), tumor size $(<2, \geq 2 \mathrm{~cm})$, and nodal involvement (yes, no), using Wilcoxon rank-sum and Kruskal-Wallis tests. ER, PR, and HER2 statuses were assessed as described previously [40].

We used unconditional nominal polytomous logistic regression to assess whether associations between fatty acids (as continuous variables based on the medians of tertiles among controls, Additional file 1: Supplemental Methods) and breast cancer risk varied by breast tumor subtypes [52], defined according to low or high expression of immuno-inflammatory markers and FAS. Models were adjusted for matching factors and the following potential confounders identified a priori using directed acyclic graphs [53]: age at menarche $(<12,12,13, \geq 14$ years), parity/age at first birth (nulliparous, 1-2 births/ age first birth $<25,1-2$ births/age first birth $\geq 25, \geq 3$ births/age first birth $<25, \geq 3$ births/age first birth $\geq 25$ ), history of breastfeeding (yes, no), family history of breast cancer (yes, no), history of biopsy-confirmed benign breast disease (yes, no), body mass index (BMI) at age $18\left(<21,21\right.$ to $\left.<23, \geq 23 \mathrm{~kg} / \mathrm{m}^{2}\right)$, weight change between age 18 and blood collection (continuous, $\mathrm{kg}$ ), average alcohol consumption from 1991 and 1995 questionnaires $(<5, \geq 5 \mathrm{~g} /$ day), and average physical activity from 1989 , 1991, and 1997 questionnaires $(<3,3$ to $<9,9$ to $<18$, 18 to $<27, \geq 27$ Metabolic Equivalent of Task [MET]hours/week). Covariates were obtained from the questionnaire administered at the time of blood collection or the biennial questionnaire immediately preceding blood collection. For covariates with missing data $(<1 \%)$, we imputed either the mode (categorical variables) or the median (continuous variables). The effects of covariates were allowed to vary by tumor subtype (i.e., models were unconstrained). The Wald test was used to test for heterogeneity using the model-based variance-covariance matrix estimate.

We estimated odds ratios (OR) and 95\% confidence intervals (CI) for the associations between fatty acids 
(categorized based on tertile cutpoints among controls) and breast cancer risk separately by tumor tissue expression subtype using unconditional logistic regression adjusted for matching factors and potential confounders. This approach allowed for the use of all controls. Results were consistent when alternatively using conditional logistic regression based on matched case-control pairs. We examined linear trends by modeling the median of each tertile as a continuous variable, testing for linearity using the Wald test. Potential non-linearity was assessed non-parametrically using restricted cubic splines [54] with knots placed at the 5th, 27.5th, 50th, 72.5th, and 95th percentiles. A likelihood ratio test compared the model with only the linear term to the model with the linear term and the cubic spline terms.

We also performed several pre-specified sensitivity analyses. First, in order to evaluate evidence for potential selection bias arising from the availability of tumor tissue, we used descriptive statistics to compare the characteristics of breast cancer cases with tumor tissue data who were included in this analysis to breast cancer cases who did not have tumor tissue data but were otherwise eligible for inclusion $(n=344)$. We also recalculated the primary heterogeneity tests and stratified analyses using inverse probability weights to account for potential selection bias arising from tumor tissue availability (Additional file 1: Supplemental Methods). Second, as there is evidence to suggest associations may vary by menopausal status [22], we repeated the primary heterogeneity analyses after restricting to women who were premenopausal at blood collection. Third, we assessed Spearman correlations between BMI at blood collection and continuous tumor marker expression levels (as measured in primary analyses). All statistical tests were two-sided. Analyses were conducted using

Table 1 Baseline characteristics of breast cancer cases and matched controls, Nurses' Health Study II

\begin{tabular}{|c|c|c|}
\hline Characteristic $^{1}$ & Cases $(n=235)$ & Controls $(n=235)$ \\
\hline Age at blood collection (years), median (IQR) ${ }^{2}$ & $45.8(42.5-49.0)$ & $45.9(42.6-49.2)$ \\
\hline Age at menarche (years), median (IQR) & $12.0(12.0-13.0)$ & $13.0(12.0-13.0)$ \\
\hline White race, $\%^{2}$ & 98.7 & 98.3 \\
\hline BMl at age $18\left(\mathrm{~kg} / \mathrm{m}^{2}\right)$, median (IQR) & $20.2(18.8-22.3)$ & $20.6(19.1-22.3)$ \\
\hline BMI at blood collection $\left(\mathrm{kg} / \mathrm{m}^{2}\right)$, median (IQR) & $24.3(21.7-27.9)$ & $24.3(21.7-28.1)$ \\
\hline Weight change from age 18 to blood collection (kg), median (IQR) & $10.5(4.5-18.2)$ & $9.5(4.1-17.7)$ \\
\hline Fasting at blood collection ( $\geq 8 \mathrm{~h}$ since last meal), $\%^{2}$ & 71.9 & 74.0 \\
\hline \multicolumn{3}{|l|}{ Menopausal status at blood collection, $\%^{2}$} \\
\hline Premenopausal & 75.7 & 74.5 \\
\hline Postmenopausal & 12.3 & 14.5 \\
\hline Unknown & 11.9 & 11.1 \\
\hline Parous women, \% & 79.6 & 82.6 \\
\hline Parity, median $(\mathrm{IQR})^{3}$ & $2.0(2.0-3.0)$ & $2.0(2.0-3.0)$ \\
\hline Age at first birth (years), median (IQR) ${ }^{3}$ & $26.0(23.0-29.0)$ & $25.0(22.0-28.0)$ \\
\hline History of breastfeeding, $\%^{3}$ & 74.3 & 77.8 \\
\hline History of biopsy-confirmed benign breast disease, $\%$ & 20.9 & 16.2 \\
\hline Family history of breast cancer, $\%$ & 15.7 & 9.8 \\
\hline NSAIDs current regular use ( $\geq 2$ times/week), \% & 14.9 & 13.6 \\
\hline Physical activity (MET-hours/week), median (IQR) & $12.1(7.1-22.2)$ & $14.0(7.3-27.9)$ \\
\hline Alcohol consumption (grams/day), median (IQR) & $1.4(0.0-6.2)$ & $1.0(0.0-3.8)$ \\
\hline Total fat consumption (\% energy intake), median (IQR) & $29.8(25.5-34.3)$ & $30.6(25.5-35.0)$ \\
\hline Total saturated fat consumption (\% energy intake), median (IQR) & $10.4(8.4-12.3)$ & $10.5(8.6-12.6)$ \\
\hline Total monounsaturated fat consumption (\% energy intake), median (IQR) & $11.6(9.6-13.5)$ & $11.9(10.1-13.6)$ \\
\hline Total polyunsaturated fat consumption (\% energy intake), median (IQR) & $4.8(4.2-5.5)$ & $4.6(4.0-5.4)$ \\
\hline
\end{tabular}

Abbreviations: IQR interquartile range, BMI body mass index, NSAIDs non-steroidal anti-inflammatory medications, MET metabolic equivalent of task

${ }^{1}$ Values are missing for age at menarche $(0.9 \%)$, age at first birth among parous women $(0.8 \%)$, NSAIDs current regular use $(3.0 \%)$, physical activity $(0.2 \%)$, alcohol consumption $(0.6 \%)$, total fat consumption $(4.9 \%)$, total saturated fat consumption $(4.9 \%)$, total monounsaturated fat consumption $(4.9 \%)$, and total polyunsaturated fat consumption $(4.9 \%)$

${ }^{2}$ Case-control matching factor

${ }^{3}$ Parity, age at first birth, and history of breast feeding among parous women 
SAS software version 9.4. (SAS Institute Inc., Cary, NC, USA).

\section{Results}

Breast cancer cases and controls were similar with regard to most baseline demographic and epidemiologic characteristics (Table 1). However, compared to controls, cases were less likely to be parous, to have breastfed, and to be physically active. Cases were also more likely to have a history of biopsy-confirmed benign breast disease and a family history of breast cancer. The majority of cases were premenopausal both at baseline blood collection (75.7\%) and at cancer diagnosis (64.7\%). Median age at breast cancer diagnosis was 49.9 years (interquartile range [IQR] 46.1-52.5), and median time between blood collection and diagnosis was 3.4 years (IQR 1.6-5.9). Concentrations of fatty acids among cases and controls are shown in Additional file 1: Supplemental Table 1.

Immune marker expression levels and correlations are shown in Additional file 1: Supplemental Table 2. Median percent positivity varied across immune markers, with the lowest levels observed for CD20 $(0.6 \%$ in stroma) and the highest levels observed for CD163 (13.2\% in stroma). Within the same tumor cell compartment, correlations between immune markers were generally higher in epithelium than in stroma. The highest correlations were observed for CD8 with CD20 (Spearman rho $=0.70)$ and CD4 $($ rho $=0.69)$ within epithelium. Correlations between epithelial and stromal cells for the same marker ranged from 0.46 for CD163 to 0.79 for CD8. Agreement between automated and manual assessments varied across markers. Spearman correlations were 0.53 for $\mathrm{CD} 4,0.72$ for $\mathrm{CD} 8,0.64$ for $\mathrm{CD} 20$, and 0.11 for CD163 in stromal cells and 0.49 for FAS in epithelial cells. ICCs across cores from the same participant ranged from 0.38 for CD20 to 0.80 for COX-2.

Some tumor markers were associated with other tumor characteristics at diagnosis, notably FAS, which was overexpressed in ER+ tumors, PR+ tumors, and tumors of lower grade, COX-2, which was overexpressed in HER2 - tumors, and CD4, which was overexpressed in tumors without nodal involvement (Table 2). All markers also tended to be more highly expressed in tumors that were smaller and lacked nodal involvement.

When we analyzed associations between fatty acid groups and subsequent breast cancer risk by tumor tissue expression subtype, no convincing evidence of heterogeneity was observed by CD4, CD20, CD163, or COX-2 expression (Table 3). However, some PUFAs differed by CD8 expression, including n-3 PUFAs which were inversely associated with $\mathrm{CD} 8^{\text {low }}$ tumors $\left(\mathrm{OR}_{\mathrm{T} 3}\right.$ vs $\mathrm{T} 1=0.45,95 \%$ CI $0.23-0.87, P_{\text {trend }}=0.02$ ) but not clearly associated with $\mathrm{CD} 8^{\text {high }}$ tumors $\left(\mathrm{OR}_{\mathrm{T} 3}\right.$ vs $\mathrm{T} 1=1.19,95 \%$ CI $0.62-2.26, P_{\text {trend }}=0.62 ; P_{\text {het }}=0.04$, degree of etiologic heterogeneity [ratio of $\mathrm{OR}_{\mathrm{T} 3}$ vs $\mathrm{T} 1$ for $\mathrm{CD} 8^{\text {high }}$ vs. $\mathrm{CD} 8^{\text {low }}$ subtypes] $=2.64$ ). This difference was largely driven by docosahexaenoic acid (DHA), which was inversely associated with $\mathrm{CD} 8^{\text {low }}$ but not $\mathrm{CD} 8^{\text {high }}$ tumors (Additional file 2: Supplemental Table 3). Statistical heterogeneity by CD8 expression levels was also observed for n-6 PUFAs, where there was a suggestive inverse association with $\mathrm{CD} 8^{\text {high }}$ tumors $\left(\mathrm{OR}_{\mathrm{T} 3}\right.$ vs $\mathrm{T} 1=0.61,95 \%$ CI $\left.0.32-1.14, P_{\text {trend }}=0.11\right)$ but a suggestive positive association with $\mathrm{CD} 8^{\text {low }}$ tumors $\left(\mathrm{OR}_{\mathrm{T} 3}\right.$ vs T1 $=1.63,95 \% \mathrm{CI}$ $0.87-3.04, P_{\text {trend }}=0.12 ; P_{\text {het }}=0.02$, degree of etiologic heterogeneity [ratio of $\mathrm{OR}_{\mathrm{T} 3}$ vs T1 for $\mathrm{CD} 8^{\text {high }}$ vs. $\mathrm{CD} 8^{\text {low }}$ subtypes $]=0.37) \quad($ Table 3$)$. Although it was not clear which individual n-6 PUFAs were driving this heterogeneity, linoleic acid showed the most similar pattern of results overall, and aolrenic acid was suggestively positively associated with $\mathrm{CD} 8^{\text {low }}$ tumors only (Additional file 2: Supplemental Table 3). In addition, the ratio of total n-6/n-3 PUFAs was associated with increased risk of $\mathrm{CD} 8^{\text {low }}$ but not $\mathrm{CD} 8^{\text {high }}$ breast cancer.

There was also heterogeneity for total MUFAs, which did not appear to be associated with tumors with a low $\mathrm{CD} 4 / \mathrm{CD} 8$ ratio $\left(\mathrm{OR}_{\mathrm{T} 3}\right.$ vs $\mathrm{T} 1=1.22,95 \%$ CI $0.62-2.40$, $\left.P_{\text {trend }}=0.52\right)$ but were inversely associated with tumors with a high $\mathrm{CD} 4 / \mathrm{CD} 8$ ratio $\left(\mathrm{OR}_{\mathrm{T} 3}\right.$ vs $\mathrm{T} 1=0.48,95 \% \mathrm{CI}$ $0.24-0.96, P_{\text {trend }}=0.04 ; P_{\text {het }}=0.008$, degree of etiologic heterogeneity [ratio of $\mathrm{OR}_{\mathrm{T} 3}$ vs $\mathrm{T} 1$ for high vs. low $\mathrm{CD} 4 /$ CD8 ratio subtypes] $=0.39$ ) (Table 3$)$. Among the individual MUFAs, this same pattern was observed for oleic acid and palmitoleic acid (Additional file 2: Supplemental Table 3).

Associations between total trans fatty acids and breast cancer risk varied by FAS expression levels (Table 4). Total trans fatty acids were not associated with FAS ${ }^{\text {low }}$ tumors $\left(\mathrm{OR}_{\mathrm{T} 3}\right.$ vs $\mathrm{T} 1=0.99,95 \% \mathrm{CI} 0.52-1.92, P_{\text {trend }}=$ $0.97)$, whereas they were positively associated with FAShigh tumors $\left(\mathrm{OR}_{\mathrm{T} 3}\right.$ vs T1 $=2.94,95 \% \mathrm{CI} 1.46-5.91, P_{\text {trend }}=$ $0.002 ; P_{\text {het }}=0.01$, degree of etiologic heterogeneity [ratio of $\mathrm{OR}_{\mathrm{T} 3}$ vs $\mathrm{T} 1$ for $\mathrm{FAS}^{\text {high }}$ vs. FAS ${ }^{\text {low }}$ subtypes] $=2.97$ ). This finding was mainly driven by 18:1 trans fatty acids, and a similar association was also observed with all industrial trans fatty acids (Additional file 2: Supplemental Table 3).

For most fatty acid groups, there was no evidence of a non-linear relationship with subtype-specific breast cancer risk. However, total saturated and monounsaturated fatty acids showed potential evidence of non-linearity across multiple subtypes ( $P$ values for non-linearity $\leq$ $0.25)$. Nevertheless, qualitative comparisons of the spline graphs did not provide strong evidence of heterogeneity by tumor subtype beyond that which was identified in the primary analyses.

Heterogeneity findings differed in epithelial cells vs. stromal cells for several fatty acids (Additional file 2: 
Table 2 Associations between breast tumor markers and other tumor characteristics at diagnosis, Nurses' Health Study II

\begin{tabular}{|c|c|c|c|c|c|c|c|}
\hline \multirow[t]{2}{*}{ Other tumor characteristics } & \multirow[t]{2}{*}{$n^{1}$} & \multicolumn{6}{|c|}{$\begin{array}{l}\text { Breast tumor markers } \\
\text { percent positivity, median (IQR) }\end{array}$} \\
\hline & & CD4 & CD8 & CD20 & CD163 & COX-2 & FAS \\
\hline \multicolumn{8}{|l|}{ ER status } \\
\hline ER+ & 162 & $3.4(1.5-9.6)$ & $5.5(2.4-10.9)$ & $0.5(0.1-1.7)$ & $13.4(9.9-16.7)$ & $26.3(13.6-43.9)$ & $86.3(74.1-90.6)$ \\
\hline ER- & 41 & $3.5(1.2-11.7)$ & $8.2(1.7-16.3)$ & $0.3(0.0-3.1)$ & $12.9(10.8-17.6)$ & $25.2(12.5-38.3)$ & $73.1(39.3-88.3)$ \\
\hline$P$ value $^{3}$ & & 0.78 & 0.36 & 0.79 & 0.75 & 0.66 & 0.001 \\
\hline \multicolumn{8}{|l|}{ PR status } \\
\hline PR+ & 144 & $3.4(1.5-9.0)$ & $5.5(2.3-10.9)$ & $0.4(0.1-1.7)$ & $13.3(9.9-16.7)$ & $26.5(13.9-43.9)$ & $87.6(76.1-91.1)$ \\
\hline PR- & 58 & $3.5(1.5-12.4)$ & $5.9(2.0-15.4)$ & $0.4(0.1-2.9)$ & $13.3(10.9-18.4)$ & $24.3(12.3-43.3)$ & $72.3(41.0-85.5)$ \\
\hline$P$ value ${ }^{3}$ & & 0.35 & 0.50 & 0.81 & 0.29 & 0.51 & $<0.001$ \\
\hline \multicolumn{8}{|l|}{ HER2 status } \\
\hline HER2+ & 27 & $5.0(2.1-7.9)$ & $6.2(2.6-13.2)$ & $0.6(0.1-1.8)$ & $13.5(9.0-17.5)$ & $16.0(10.6-28.0)$ & $85.4(73.2-92.4)$ \\
\hline HER2- & 104 & $3.0(1.5-10.1)$ & $7.0(2.3-13.1)$ & $0.4(0.1-1.8)$ & $13.3(10.2-16.6)$ & $29.9(17.9-43.9)$ & $84.1(68.0-89.3)$ \\
\hline$P$ value ${ }^{3}$ & & 0.55 & 0.94 & 0.88 & 0.94 & 0.05 & 0.44 \\
\hline \multicolumn{8}{|l|}{ Tumor grade } \\
\hline Grade I & 41 & $3.3(1.1-6.7)$ & $4.8(1.9-8.7)$ & $0.6(0.1-3.1)$ & $12.5(9.4-16.1)$ & $28.2(12.6-50.9)$ & $88.6(80.4-94.8)$ \\
\hline Grade II & 71 & $2.4(1.3-9.1)$ & $5.7(2.0-13.1)$ & $0.4(0.1-1.7)$ & $13.3(9.9-16.7)$ & $25.4(13.4-42.9)$ & $84.6(68.7-90.2)$ \\
\hline Grade III & 58 & $3.0(1.5-8.3)$ & $7.6(2.7-15.4)$ & $0.2(0.0-1.2)$ & $13.4(10.8-16.5)$ & $29.9(15.2-43.3)$ & $80.1(63.6-88.2)$ \\
\hline$P$ value ${ }^{3}$ & & 0.90 & 0.19 & 0.14 & 0.50 & 0.80 & 0.003 \\
\hline \multicolumn{8}{|l|}{ Tumor size } \\
\hline$<2 \mathrm{~cm}$ & 126 & $3.6(1.5-9.0)$ & $6.6(2.2-12.3)$ & $0.4(0.1-1.7)$ & $13.3(10.2-16.7)$ & $29.2(14.8-45.0)$ & 84.5 (70.6-89.3) \\
\hline$\geq 2 \mathrm{~cm}$ & 50 & $2.1(1.0-5.5)$ & $5.5(1.7-10.9)$ & $0.2(0.1-1.0)$ & $12.8(10.4-16.5)$ & $24.1(12.0-43.3)$ & $83.6(69.3-91.1)$ \\
\hline$P$ value 3 & & 0.06 & 0.58 & 0.30 & 0.67 & 0.25 & 0.76 \\
\hline \multicolumn{8}{|l|}{ Nodal involvement } \\
\hline No & 141 & $4.4(1.6-9.9)$ & $6.8(2.3-13.1)$ & $0.7(0.1-2.1)$ & $13.3(10.3-16.7)$ & $30.0(15.0-45.5)$ & $85.4(70.8-89.9)$ \\
\hline Yes & 58 & $2.1(1.0-7.2)$ & $5.5(2.2-10.8)$ & $0.2(0.1-2.0)$ & $13.0(10.1-16.7)$ & $22.1(12.0-38.6)$ & $83.0(64.7-90.0)$ \\
\hline$P$ value $^{3}$ & & 0.02 & 0.54 & 0.19 & 0.84 & 0.06 & 0.46 \\
\hline
\end{tabular}

Abbreviations: IQR interquartile range, COX-2 cyclooxygenase-2, ER estrogen receptor, $P R$ progesterone receptor, HER2 human epidermal growth factor receptor 2 ${ }^{1}$ Total $n$ varies across markers depending on the number of cases with data for each marker

${ }^{2}$ Measured in stroma (CD4, CD8, CD20, CD163) or epithelium (COX-2, FAS). COX-2 was defined as the percentage of epithelial area staining positive for at least one of the two antibodies (Cayman Chemical or Thermo Fisher Scientific)

${ }^{3} P$ value calculated using a Wilcoxon rank-sum test (tumor characteristics with two categories) or a Kruskal-Wallis test (tumor characteristics with three categories)

Supplemental Table 3). For example, the heterogeneity by CD8 expression observed for total $n-3$ and $n-6$ PUFAs was not observed in epithelial cells. Some heterogeneity findings for COX-2 also varied when comparing the two commercial antibodies.

In sensitivity analyses, the 235 breast cancer cases included in this analysis differed from the 344 cases without tumor tissue who were otherwise eligible for inclusion with regard to year of diagnosis, tumor invasiveness and size, HER2 enrichment, menopausal status at diagnosis, and some breast cancer risk factors (Additional file 1: Supplemental Table 4). However, after using inverse probability weights to account for potential selection bias, the pattern of results was not substantially altered, though statistical power was lower (Additional file 1: Supplemental Table 5). The pattern of heterogeneity findings was also similar after restricting the analyses to women who were premenopausal at blood collection (Additional file 1: Supplemental Table 6). In addition, tumor marker expression levels were not strongly correlated with BMI at blood collection (all Spearman correlations $\leq 0.10$, except for COX $-2[$ rho $=0.14]$ and CD8 [rho $=0.13]$ ). Finally, for breast cancer associations with the strongest evidence of heterogeneity by tumor subtype, plots of continuous fatty acid concentrations and tumor marker expression levels are shown in Additional file 1: Supplemental Fig. 1.

\section{Discussion}

We prospectively evaluated the relationship between circulating fatty acids and breast cancer risk in what is, to our knowledge, the first study to leverage tumor tissue to assess heterogeneity by expression levels of immuno- 
Table 3 Multivariable-adjusted odds ratios ( $95 \%$ Cl) for associations between tertiles of total erythrocyte fatty acid concentrations and subsequent breast cancer risk, stratified by tumor expression of immuno-inflammatory markers, Nurses' Health Study II

\begin{tabular}{|c|c|c|c|c|c|c|c|c|c|}
\hline & Tertile 1 & Tertile 2 & Tertile 3 & $P_{\text {trend }}{ }^{1}$ & Tertile 1 & Tertile 2 & Tertile 3 & $P_{\text {trend }}{ }^{1}$ & $P_{\text {het }}^{2}$ \\
\hline & \multicolumn{4}{|c|}{$\mathrm{CD}^{\text {low }}(n=109)^{3}$} & \multicolumn{5}{|c|}{$\mathrm{CD}^{\text {high }}(n=110)^{3}$} \\
\hline Saturated fatty acids & 1 (ref) & $0.39(0.20-0.76)$ & $0.93(0.51-1.71)$ & 0.80 & 1 (ref) & $0.50(0.26-0.96)$ & $0.98(0.55-1.75)$ & 0.77 & 0.94 \\
\hline Monounsaturated fatty acids & 1 (ref) & $0.93(0.49-1.76)$ & $0.84(0.43-1.67)$ & 0.63 & 1 (ref) & $0.75(0.40-1.40)$ & $0.85(0.45-1.60)$ & 0.63 & 0.80 \\
\hline n-3 polyunsaturated fatty acids & 1 (ref) & $0.72(0.37-1.38)$ & $0.81(0.43-1.53)$ & 0.55 & 1 (ref) & $0.77(0.41-1.45)$ & $0.69(0.37-1.30)$ & 0.26 & 0.61 \\
\hline n-6 polyunsaturated fatty acids & 1 (ref) & $0.57(0.30-1.08)$ & $0.93(0.50-1.74)$ & 0.80 & 1 (ref) & $0.80(0.43-1.49)$ & $1.00(0.55-1.82)$ & 1.00 & 0.84 \\
\hline \multirow[t]{2}{*}{ Trans fatty acids } & 1 (ref) & $0.98(0.51-1.88)$ & $1.66(0.85-3.23)$ & 0.12 & 1 (ref) & $1.50(0.80-2.82)$ & $1.52(0.78-2.94)$ & 0.25 & 0.75 \\
\hline & \multicolumn{4}{|c|}{ CD8 $8^{\text {low }}(n=104)^{3}$} & \multicolumn{5}{|c|}{$\mathrm{CD}^{\text {high }}(n=105)^{3}$} \\
\hline Saturated fatty acids & 1 (ref) & $0.43(0.23-0.83)$ & $0.74(0.40-1.34)$ & 0.53 & 1 (ref) & $0.44(0.22-0.86)$ & $1.12(0.61-2.05)$ & 0.42 & 0.34 \\
\hline Monounsaturated fatty acids & 1 (ref) & $0.88(0.47-1.65)$ & $0.81(0.42-1.58)$ & 0.55 & 1 (ref) & $0.78(0.41-1.48)$ & $0.83(0.43-1.61)$ & 0.60 & 0.72 \\
\hline $\mathrm{n}-3$ polyunsaturated fatty acids & 1 (ref) & $0.49(0.25-0.95)$ & $0.45(0.23-0.87)$ & 0.02 & 1 (ref) & $1.14(0.60-2.17)$ & $1.19(0.62-2.26)$ & 0.62 & 0.04 \\
\hline $\mathrm{n}-6$ polyunsaturated fatty acids & 1 (ref) & $1.19(0.62-2.28)$ & $1.63(0.87-3.04)$ & 0.12 & 1 (ref) & $0.57(0.31-1.08)$ & $0.61(0.32-1.14)$ & 0.11 & 0.02 \\
\hline \multirow[t]{2}{*}{ Trans fatty acids } & 1 (ref) & $1.23(0.64-2.35)$ & $1.95(1.00-3.82)$ & 0.05 & 1 (ref) & $1.37(0.72-2.61)$ & $1.56(0.79-3.08)$ & 0.21 & 0.51 \\
\hline & \multicolumn{4}{|c|}{ CD20 low $(n=103)^{3}$} & \multicolumn{5}{|c|}{$\mathrm{CD} 20^{\text {high }}(n=104)^{3}$} \\
\hline Saturated fatty acids & 1 (ref) & $0.61(0.32-1.16)$ & $1.17(0.64-2.16)$ & 0.42 & 1 (ref) & $0.25(0.12-0.52)$ & $0.79(0.43-1.45)$ & 0.83 & 0.72 \\
\hline Monounsaturated fatty acids & 1 (ref) & $1.05(0.56-1.97)$ & $0.75(0.38-1.49)$ & 0.39 & 1 (ref) & $0.73(0.39-1.39)$ & $0.92(0.47-1.77)$ & 0.78 & 0.55 \\
\hline n-3 polyunsaturated fatty acids & 1 (ref) & $0.74(0.38-1.43)$ & $0.66(0.34-1.29)$ & 0.24 & 1 (ref) & $0.75(0.39-1.45)$ & $0.88(0.47-1.67)$ & 0.74 & 0.76 \\
\hline $\mathrm{n}-6$ polyunsaturated fatty acids & 1 (ref) & $0.71(0.37-1.34)$ & $0.78(0.42-1.46)$ & 0.44 & 1 (ref) & $0.74(0.38-1.43)$ & $1.32(0.72-2.44)$ & 0.36 & 0.32 \\
\hline \multirow[t]{2}{*}{ Trans fatty acids } & 1 (ref) & $0.99(0.52-1.91)$ & $1.71(0.87-3.37)$ & 0.11 & 1 (ref) & $1.73(0.89-3.34)$ & $1.77(0.89-3.53)$ & 0.13 & 0.73 \\
\hline & \multicolumn{4}{|c|}{ CD163 $3^{\text {low }}(n=110)^{3}$} & \multicolumn{5}{|c|}{ CD163 ${ }^{\text {high }}(n=111)^{3}$} \\
\hline Saturated fatty acids & 1 (ref) & $0.35(0.18-0.69)$ & $1.04(0.58-1.88)$ & 0.55 & 1 (ref) & $0.57(0.31-1.06)$ & $0.87(0.49-1.56)$ & 0.85 & 0.66 \\
\hline Monounsaturated fatty acids & 1 (ref) & $0.86(0.46-1.61)$ & $0.85(0.44-1.67)$ & 0.65 & 1 (ref) & $0.76(0.41-1.40)$ & $0.82(0.44-1.53)$ & 0.54 & 0.81 \\
\hline n-3 polyunsaturated fatty acids & 1 (ref) & $0.82(0.43-1.58)$ & $1.02(0.54-1.93)$ & 0.88 & 1 (ref) & $0.70(0.37-1.30)$ & $0.58(0.31-1.08)$ & 0.09 & 0.13 \\
\hline n-6 polyunsaturated fatty acids & 1 (ref) & $0.91(0.49-1.70)$ & $0.98(0.53-1.81)$ & 0.94 & 1 (ref) & $0.54(0.29-1.02)$ & $0.94(0.53-1.68)$ & 0.79 & 0.76 \\
\hline \multirow[t]{2}{*}{ Trans fatty acids } & 1 (ref) & $1.19(0.63-2.23)$ & $1.51(0.78-2.95)$ & 0.22 & 1 (ref) & $1.28(0.68-2.41)$ & $1.92(1.01-3.67)$ & 0.05 & 0.64 \\
\hline & \multicolumn{4}{|c|}{ Low CD4/CD8 ratio $(n=100)^{3}$} & \multicolumn{5}{|c|}{ High CD4/CD8 ratio $(n=100)^{3}$} \\
\hline Saturated fatty acids & 1 (ref) & $0.29(0.14-0.59)$ & $0.90(0.49-1.64)$ & 0.85 & 1 (ref) & $0.66(0.35-1.26)$ & $1.00(0.54-1.86)$ & 0.83 & 0.88 \\
\hline Monounsaturated fatty acids & 1 (ref) & $0.91(0.47-1.77)$ & $1.22(0.62-2.40)$ & 0.52 & 1 (ref) & $0.67(0.36-1.26)$ & $0.48(0.24-0.96)$ & 0.04 & 0.008 \\
\hline n-3 polyunsaturated fatty acids & 1 (ref) & $0.88(0.46-1.71)$ & $0.93(0.48-1.80)$ & 0.86 & 1 (ref) & $0.69(0.36-1.32)$ & $0.58(0.30-1.12)$ & 0.11 & 0.20 \\
\hline n-6 polyunsaturated fatty acids & 1 (ref) & $0.62(0.33-1.16)$ & $0.75(0.40-1.43)$ & 0.36 & 1 (ref) & $0.97(0.50-1.88)$ & $1.30(0.69-2.46)$ & 0.40 & 0.11 \\
\hline \multirow[t]{2}{*}{ Trans fatty acids } & 1 (ref) & $1.54(0.79-3.02)$ & $1.77(0.87-3.59)$ & 0.13 & 1 (ref) & $1.25(0.65-2.39)$ & $1.76(0.90-3.44)$ & 0.10 & 0.62 \\
\hline & \multicolumn{4}{|c|}{$\operatorname{cox}-2^{\text {low }}(n=103)^{3}$} & \multicolumn{5}{|c|}{$\operatorname{COX}-2^{\text {high }}(n=104)^{3}$} \\
\hline Saturated fatty acids & 1 (ref) & $0.47(0.24-0.89)$ & $0.90(0.50-1.65)$ & 0.99 & 1 (ref) & $0.38(0.19-0.75)$ & $1.10(0.61-1.98)$ & 0.39 & 0.34 \\
\hline Monounsaturated fatty acids & 1 (ref) & $0.84(0.45-1.58)$ & $0.86(0.45-1.65)$ & 0.65 & 1 (ref) & $0.81(0.44-1.51)$ & $0.72(0.37-1.42)$ & 0.35 & 0.73 \\
\hline n-3 polyunsaturated fatty acids & 1 (ref) & $0.46(0.23-0.89)$ & $0.60(0.31-1.13)$ & 0.14 & 1 (ref) & $1.08(0.58-2.01)$ & $0.82(0.43-1.56)$ & 0.53 & 0.76 \\
\hline $\mathrm{n}-6$ polyunsaturated fatty acids & 1 (ref) & $0.94(0.49-1.81)$ & $1.36(0.74-2.52)$ & 0.31 & 1 (ref) & $0.59(0.32-1.09)$ & $0.69(0.37-1.29)$ & 0.23 & 0.06 \\
\hline Trans fatty acids & 1 (ref) & $1.32(0.71-2.47)$ & $1.65(0.83-3.26)$ & 0.15 & 1 (ref) & $1.39(0.71-2.72)$ & $2.08(1.06-4.07)$ & 0.03 & 0.24 \\
\hline
\end{tabular}

Cases and controls were matched on case diagnosis date, age at blood collection ( \pm 2 years), menopausal status at blood collection and in the questionnaire cycle before cancer diagnosis/control index date (premenopausal, postmenopausal, unknown), self-reported race/ethnicity (white, non-white), fasting status at blood collection ( $<2,2-4$, $5-7,8-11, \geq 12 \mathrm{~h}$ since last meal), and month ( \pm 1 month) and time of day $( \pm 2 \mathrm{~h}$ ) of blood collection. Women who were premenopausal at blood collection and provided samples timed in the menstrual cycle were further matched on luteal day ( \pm 1 day), and postmenopausal women were further matched on menopausal hormone therapy use at blood collection (yes, no). Tertiles of fatty acids were defined based on tertile cutpoints among controls (Additional file 1: Supplemental Methods). Multivariable unconditional logistic regression models were adjusted for matching factors and the following potential confounders: age at menarche $(<12,12,13, \geq 14$ years), parity/age at first birth (nulliparous, $1-2$ births/age first birth $<25,1-2$ births/age first birth $\geq 25, \geq 3$ births/age first birth $<25, \geq 3$ births/age first birth $\geq 25$ ), history of breastfeeding (yes, no), family history of breast cancer (yes, no), history of biopsy-confirmed benign breast disease (yes, no), BMl at age $18\left(<21,21\right.$ to $\left.<23, \geq 23 \mathrm{~kg} / \mathrm{m}^{2}\right)$, weight change between age 18 and blood collection (continuous, $\mathrm{kg}$ ), average alcohol consumption from 1991 and 1995 questionnaires $(<5, \geq 5 \mathrm{~g} /$ day), and average physical activity from 1989 , 1991, and 1997 questionnaires ( $<3,3$ to $<9,9$ to $<18,18$ to $<27, \geq 27$ Metabolic Equivalent of Task [MET]-hours/week) Abbreviations: $\mathrm{Cl}$ confidence interval, $\mathrm{COX}-2$ cyclooxygenase-2

${ }^{1} P$ trend calculated by modeling the median of each tertile among controls as a continuous variable, testing for linearity using the Wald test

${ }^{2} P$ heterogeneity calculated using unconditional nominal polytomous logistic regression adjusted for matching factors and confounders, testing for heterogeneity using the Wald test with the model-based variance-covariance matrix estimate and allowing the effects of covariates to vary by tumor subtype

${ }^{3}$ Low vs. high tumor expression subtype was based on the median percent positivity in stromal cells for CD4 (4.2\%), CD8 (5.5\%), CD20 (0.6\%), CD163 (13.2\%), and CD4/CD8 ratio (0.7) and on the median percent positivity in epithelial cells for COX-2 (26.9\%). COX-2 was defined as the percentage of epithelial area staining positive for at least one of the two antibodies (Cayman Chemical or Thermo Fisher Scientific) 
Table 4 Multivariable-adjusted odds ratio $(95 \% \mathrm{CI})$ for associations between tertiles of total erythrocyte fatty acid concentrations and subsequent breast cancer risk, stratified by tumor expression of fatty acid synthase (FAS), Nurses' Health Study II

\begin{tabular}{|c|c|c|c|c|c|c|c|c|c|}
\hline & Tertile 1 & Tertile 2 & Tertile 3 & $P_{\text {trend }}{ }^{1}$ & Tertile 1 & Tertile 2 & Tertile 3 & $P_{\text {trend }}{ }^{1}$ & $P_{\text {het }}{ }^{2}$ \\
\hline & \multicolumn{4}{|c|}{ FAS $^{\text {low }}(n=108)^{3}$} & \multicolumn{5}{|c|}{ FAS $^{\text {high }}(n=108)^{3}$} \\
\hline Saturated fatty acids & 1 (ref) & $0.46(0.24-0.88)$ & $0.90(0.49-1.64)$ & 0.97 & 1 (ref) & $0.46(0.24-0.89)$ & $1.11(0.62-1.99)$ & 0.44 & 0.67 \\
\hline Monounsaturated fatty acids & 1 (ref) & $0.84(0.45-1.60)$ & $0.99(0.51-1.89)$ & 0.99 & 1 (ref) & $0.75(0.40-1.39)$ & $0.61(0.31-1.17)$ & 0.14 & 0.19 \\
\hline n-3 polyunsaturated fatty acids & 1 (ref) & $0.99(0.52-1.87)$ & $0.88(0.47-1.65)$ & 0.68 & 1 (ref) & $0.63(0.33-1.20)$ & $0.65(0.34-1.24)$ & 0.21 & 0.59 \\
\hline n-6 polyunsaturated fatty acids & 1 (ref) & $0.69(0.37-1.28)$ & $0.82(0.44-1.52)$ & 0.51 & 1 (ref) & $0.65(0.34-1.24)$ & $1.09(0.60-1.99)$ & 0.72 & 0.22 \\
\hline trans fatty acids & 1 (ref) & $1.15(0.62-2.15)$ & $0.99(0.52-1.92)$ & 0.97 & 1 (ref) & $1.66(0.85-3.24)$ & $2.94(1.46-5.91)$ & 0.002 & 0.01 \\
\hline
\end{tabular}

Cases and controls were matched on case diagnosis date, age at blood collection ( \pm 2 years), menopausal status at blood collection and in the questionnaire cycle before cancer diagnosis/control index date (premenopausal, postmenopausal, unknown), self-reported race/ethnicity (white, non-white), fasting status at blood collection $(<2,2-4,5-7,8-11, \geq 12 \mathrm{~h}$ since last meal), and month ( \pm 1 month) and time of day $( \pm 2 \mathrm{~h}$ ) of blood collection. Women who were premenopausal at blood collection and provided samples timed in the menstrual cycle were further matched on luteal day ( \pm 1 day), and postmenopausal women were further matched on menopausal hormone therapy use at blood collection (yes, no). Tertiles of fatty acids were defined based on tertile cutpoints among controls (Additional file 1: Supplemental Methods). Multivariable unconditional logistic regression models were adjusted for matching factors and the following potential confounders: age at menarche $(<12,12,13, \geq 14$ years), parity/age at first birth (nulliparous, $1-2$ births/age first birth $<25,1-2$ births/age first birth $\geq 25, \geq 3$ births/age first birth $<25, \geq 3$ births/age first birth $\geq 25$ ), history of breastfeeding (yes, no), family history of breast cancer (yes, no), history of biopsy-confirmed benign breast disease (yes, no), BMI at age $18\left(<21,21\right.$ to $\left.<23, \geq 23 \mathrm{~kg} / \mathrm{m}^{2}\right)$, weight change between age 18 and blood collection (continuous, $\mathrm{kg}$ ), average alcohol consumption from 1991 and 1995 questionnaires $(<5, \geq 5 \mathrm{~g} /$ day), and average physical activity from 1989, 1991, and 1997 questionnaires $(<3,3$ to $<9,9$ to $<18,18$ to $<27, \geq 27$ Metabolic Equivalent of Task [MET]-hours/week)

Abbreviations: $\mathrm{Cl}$ confidence interval, FAS fatty acid synthase

${ }^{1} P$ trend calculated by modeling the median of each tertile among controls as a continuous variable, testing for linearity using the Wald test

${ }^{2} P$ heterogeneity calculated using unconditional nominal polytomous logistic regression adjusted for matching factors and confounders, testing for heterogeneity using the Wald test with the model-based variance-covariance matrix estimate and allowing the effects of covariates to vary by tumor subtype

${ }^{3}$ Low vs. high tumor expression of fatty acid synthase is based on the median percent positivity in epithelial cells $(84.2 \%)$

inflammatory markers and FAS. Although most erythrocyte membrane fatty acids did not appear to have differential effects on breast cancer risk by tumor tissue expression subtypes, there was evidence of effect heterogeneity by CD8 and FAS expression. Results suggested a possible protective effect of $n-3$ PUFAs on $\mathrm{CD} 8^{\text {low }}$ but not $\mathrm{CD} 8^{\text {high }}$ breast tumors, while there was evidence of a potential protective effect of $n-6$ PUFAs on $\mathrm{CD} 8^{\text {high }}$ tumors only. In addition, trans fatty acids appeared to increase the risk of FAS ${ }^{\text {high }}$ but not FAS ${ }^{\text {low }}$ breast cancers. These findings provide insight into potential immunomodulatory mechanisms of $n-3$ and n-6 PUFAs as well as potential FAS-mediated mechanisms of trans fatty acids in breast carcinogenesis.

In spite of mounting experimental evidence supporting an anti-inflammatory, anti-carcinogenic effect of $n-3$ PUFAs [1], the epidemiologic evidence for a role of $n-3$ PUFAs in breast cancer risk reduction remains inconclusive. For example, while findings from a meta-analysis of 16 prospective cohort studies indicated an inverse association between marine n-3 PUFA intake and breast cancer risk (relative risk for highest vs. lowest intake 0.86 , 95\% CI 0.78-0.94) and this association was consistent in studies measuring fatty acid intake using biomarkers [55], secondary analyses of a recent randomized control trial showed less convincing evidence for a reduction in breast cancer risk following marine n-3 PUFA supplementation (hazard ratio for intervention vs. placebo 0.90, 95\% CI 0.70-1.16) [56].

In the present study, n-3 PUFAs were associated with lower risk of breast cancer only among cases with low levels of CD8 stromal cell infiltration, and this association was driven primarily by DHA. n-3 PUFAs are hypothesized to have a multifaceted role in immune regulation and inflammation, including modulation of $\mathrm{T}$ cell proliferation [1]. Preclinical research suggests that DHA and other n-3 PUFAs may reduce breast cancer risk by decreasing proinflammatory eicosanoids, generating bioactive lipid mediators involved in inflammation resolution, reducing cytokine production, modulating oncogenic protein signaling via disruption of plasma lipid membranes, and increasing apoptosis [1, 57, 58]. Our epidemiologic findings provide greater credence to the hypothesis that n-3 PUFAs may reduce breast cancer risk through these immuno-modulatory mechanisms because cytotoxic CD8 T cells have antitumorigenic properties [27], and tumors that arise in an immune microenvironment with a dearth of CD8 cells may therefore derive greater benefit from the anti-inflammatory, immuno-modulatory effects of n-3 PUFAs. These data also suggest that potential anti-carcinogenic effects of $n$ 3 PUFAs may have been obscured by breast tumor heterogeneity in some prior studies. Finally, given that low levels of CD8 cells in tumor tissue have been associated with poor breast cancer prognosis [28], our findings also support the hypothesis that interventions aimed at increasing n-3 PUFA/DHA intake may have the potential to reduce the risk of developing more aggressive breast tumors.

As with $n-3$ PUFAs, the role of $n-6$ PUFAs in breast carcinogenesis remains controversial. While some prior studies of specific circulating n-6 PUFAs suggest inverse 
associations with breast cancer risk [13, 16, 21, 22], others suggest positive associations $[9,18,19,21]$. In the present study, n-6 PUFAs were suggestively inversely associated with breast tumors with high CD8 expression but suggestively positively associated with tumors with low CD8 expression. This finding may have been driven in part by heterogeneous effects of individual n-6 PUFAs, with linoleic acid and aolrenic acid showing different patterns of association. However, an underlying biologic explanation for this differential association remains unclear. In addition, a mechanistic explanation for the differential association between MUFAs and breast cancer risk by $\mathrm{CD} 4 / \mathrm{CD} 8$ ratio remains to be elucidated.

Trans fats have also been hypothesized to influence breast cancer risk; however, the epidemiologic evidence remains insufficient and suggestive positive $[9,11-13$, 17] and inverse [9, 11] associations have been reported in previous studies of individual and total circulating trans fatty acids. Some [3-6] though not all [59-62] controlled dietary intervention studies suggest that trans fat intake may result in higher levels of circulating proinflammatory markers. Preclinical studies also suggest that trans fatty acids could promote de novo fatty acid synthesis [63, 64].

In this analysis, total trans fatty acids were positively associated with FAS ${ }^{\text {high }}$ but not FAS ${ }^{\text {low }}$ tumors, and this difference was predominantly driven by $18: 1$ and industrial trans fats. These results suggest that the effects of trans fatty acids on breast cancer risk may be mediated through FAS expression and that trans fats may increase the risk of a FAS ${ }^{\text {high }}$ breast cancer subtype. This hypothesis is supported by mechanistic studies in mice, where a diet high in trans fat produced a 2- to 3-fold increase in mRNA of FAS $[63,64]$ and a 2 -fold increase in mRNA of sterol regulatory element binding protein (SREBP)-1 [64], a transcription factor that upregulates fatty acid synthesis [65]. Breast tumor overexpression of FAS has also long been recognized as an indicator of poor clinical prognosis [66], lending greater public health importance to the hypothesis that trans fatty acids may increase the risk of breast cancers with high FAS expression.

In the present study, tumor marker expression levels were not strongly correlated with BMI at blood collection, which contrasts with the hypothesis that tumor markers indicating proinflammatory environments might be more highly expressed in obese/overweight individuals. Nevertheless, some of our heterogeneity findings by tumor tissue expression levels were similar to previously observed patterns of heterogeneity by BMI [17].

Several exposures have been differentially associated with breast cancer risk by tumor ER, PR, and HER2 status in prior studies [67]. Thus, the associations we observed between fatty acids and breast cancer subtypes may further vary by other tumor characteristics.
However, we lacked sufficient statistical power to assess differences in associations by these characteristics. Prior analyses have also illustrated that breast tumor expression of immuno-inflammatory markers and fatty acid synthase vary across established breast tumor subtypes [68-71]. In the present study, tumor expression levels of FAS, COX-2, and CD4 were associated with several other tumor characteristics. Notably, FAS was overexpressed in $\mathrm{ER}+, \mathrm{PR}+$, and low-grade tumors. Although the proliferative and metastatic capacity of FAS is wellrecognized [36], prior studies have similarly identified FAS overexpression in hormone receptor-positive and low-grade breast tumors $[68,69]$, suggesting that it may be important to consider other tumor characteristics when assessing the role of FAS in breast carcinogenesis.

Our study has several strengths, including its prospective design and unique characterization of tumors according to immuno-inflammatory markers and FAS, which allowed us to identify specific breast cancer subtypes that may be susceptible to intervention. We also comprehensively evaluated a large number of fatty acids measured in erythrocyte membranes, which incorporate both diet-derived and endogenous sources of fatty acids and capture a longer exposure window than other blood-based measurements [23]. With detailed information on breast cancer risk factors, we were able to adjust for many potential confounders.

There are also several important limitations to our study. First, our study was limited by a modest sample size which precluded additional stratification by other breast tumor subtypes. Second, we lacked tumor tissue data on approximately $60 \%$ of breast cancer cases potentially eligible for this study, which could introduce selection bias. However, results were similar after accounting for potential selection bias using inverse probability weighs. Third, the tumor microenvironment changes over time and in response to cancer therapies. Although our analysis of formalin-fixed paraffin-embedded tissue did not allow us to capture this dynamic process, we expect that most women during this time period were not undergoing treatment prior to primary breast tumor resection. Fourth, we relied on measurements from three tumor cores, which might not be representative of the entire tumor, and we measured fatty acids from a single blood sample. However, a single fatty acid measure was fairly reproducible among postmenopausal women in NHS [72], and correcting for measurement error using ICCs from a reproducibility study did not substantially alter the results in our prior analysis [17]. Fifth, we assessed multiple associations, which increases the risk of spurious findings as a result of multiple comparisons. Although our heterogeneity findings would not meet traditional thresholds for statistical significance after stringent correction for multiple comparisons, our 
analyses were guided by strong, biologically driven a priori hypotheses. Finally, the women included in this study were predominantly white and premenopausal, potentially limiting the generalizability of our findings.

\section{Conclusions}

Taken together, our findings suggest that n-3 PUFAs may decrease the risk of breast cancers that arise in an immune microenvironment with low but not high CD8 $\mathrm{T}$ cell infiltration, while n-6 PUFAs may decrease breast cancer risk in an environment of high but not low CD8 infiltration. In addition, trans fatty acids may influence the risk of breast cancers that overexpress FAS. These data provide epidemiologic evidence that the effects of specific $n-3$ and n-6 PUFAs may be mediated through modulation of the cancer immune response, while the effects of trans fatty acids may be facilitated via endogenous fatty acid synthesis. More broadly, our results underscore the importance of incorporating pathology data into epidemiologic studies in order to investigate potential effect heterogeneity and provide insights that may eventually help inform precision breast cancer prevention efforts.

\section{Supplementary information}

Supplementary information accompanies this paper at https://doi.org/10. 1186/s13058-020-01316-4

Additional file 1: Supplemental Methods, Tables, and Figures. Contains the following: Supplemental Methods. Supplemental Table 1. Concentrations of erythrocyte fatty acids (\% of total fatty acids) among cases and matched controls, Nurses' Health Study II. Supplemental Table 2. Median percent positivity and Spearman correlations of breast tumor immune markers by tumor cell compartment, Nurses' Health Study II. Supplemental Table 4. Characteristics of potentially eligible breast cancer cases by tumor tissue availability, Nurses' Health Study II.

Supplemental Table 5. Multivariable-adjusted odds ratios ( $95 \% \mathrm{Cl}$ ) for associations between tertiles of total erythrocyte fatty acid concentrations and subsequent breast cancer risk, stratified by tumor expression of immuno-inflammatory markers and fatty acid synthase (FAS), using inverse probability weights to account for potential selection bias, Nurses' Health Study II. Supplemental Table 6. Multivariable-adjusted odds ratios $(95 \% \mathrm{Cl})$ for associations between tertiles of total erythrocyte fatty acid concentrations and subsequent breast cancer risk, stratified by tumor expression of immuno-inflammatory markers and fatty acid synthase (FAS), restricted to premenopausal women at blood collection, Nurses' Health Study II. Supplemental Fig. 1. Total erythrocyte fatty acid concentrations and tumor expression of immuno-inflammatory markers and fatty acid synthase (FAS) among breast cancer cases, Nurses' Health Study II.

Additional file 2: Supplemental Table 3. Multivariable-adjusted odds ratios $(95 \% \mathrm{Cl})$ for associations between tertiles of erythrocyte fatty acid concentrations and subsequent breast cancer risk, stratified by tumor expression of immuno-inflammatory markers and fatty acid synthase (FAS), calculated separately by tumor cell compartment and COX-2 antibody, Nurses' Health Study II.

\section{Abbreviations}

PUFAs: Polyunsaturated fatty acids; NHSII: Nurses' Health Study II; COX2: Cyclooxygenase-2; FAS: Fatty acid synthase; TMA: Tumor microarray; SFA: Saturated fatty acids; MUFA: Monounsaturated fatty acids; TFA: Trans fatty acids; CV: Coefficient of variation; ICC: Intraclass correlation coefficient;
ER: Estrogen receptor; PR: Progesterone receptor; HER2: Human epidermal growth factor receptor 2; BMI: Body mass index; MET: Metabolic equivalent of task; OR: Odds ratio; Cl: Confidence interval; IQR: Interquartile range

\section{Acknowledgements}

We would like to thank the participants and staff of the Nurses' Health Study II for their valuable contributions as well as the following state cancer registries for their help: $A L, A Z, A R, C A, C O, C T, D E, F L, G A, I D, I L, I N, I A, K Y$, LA, ME, MD, MA, MI, NE, NH, NJ, NY, NC, ND, OH, OK, OR, PA, RI, SC, TN, TX, VA, WA, and WY. The authors assume full responsibility for analyses and interpretation of these data. The content is solely the responsibility of the authors and does not necessarily represent the official views of the National Institutes of Health.

\section{Authors' contributions}

Study concept and design (EEM, CHK, PS, SJ, AHE); acquisition of data (YJH, LCC, GMB, PS, SJ, RMT, AHE); statistical analysis (EEM, CHK, MW, AHE); interpretation of data (all authors); drafting of manuscript (EEM); critical review and approval of final manuscript (all authors).

\section{Funding}

This work was supported by NIH R01 CA160246, R01 CA050385, U01 CA176726, and R01 CA67262. CH Kim was funded by NIH T32 CA009001. The funding bodies had no role in the design of the study, collection, analysis, or interpretation of data, or writing of the manuscript.

\section{Availability of data and materials}

The datasets generated and/or analyzed during the current study are not publicly available due to privacy restrictions but are available from the corresponding author on reasonable request.

\section{Ethics approval and consent to participate}

This study protocol was approved by the institutional review boards of the Brigham and Women's Hospital, Harvard T.H. Chan School of Public Health, and participating registries, as required. All study participants provided written informed consent.

\section{Consent for publication}

Not applicable.

\section{Competing interests}

The authors declare that they have no competing interests.

\section{Author details}

${ }^{1}$ Channing Division of Network Medicine, Department of Medicine, Brigham and Women's Hospital and Harvard Medical School, Boston, MA, USA. ${ }^{2}$ Department of Epidemiology, Harvard T.H. Chan School of Public Health, Boston, MA, USA. ${ }^{3}$ Department of Biostatistics, Harvard T.H. Chan School of Public Health, Boston, MA, USA. ${ }^{4}$ Center on Methods for Implementation and Prevention Science (CMIPS), Yale School of Public Health, New Haven, CT, USA. ${ }^{5}$ Department of Statistics and Data Science, Yale University, New Haven, CT, USA. ${ }^{6}$ Medical Oncology, Ohio State University Comprehensive Cancer Center, Columbus, OH, USA. ${ }^{7}$ Department of Pathology, Beth Israel Deaconess Medical Center and Harvard Medical School, Boston, MA, USA. ${ }^{8}$ Department of Cell, Developmental and Cancer Biology, Oregon Health and Science University, Portland, OR, USA. ${ }^{9}$ Division of Epidemiology, Population Health Sciences, Weill Cornell Medicine, New York, NY, USA.

Received: 30 January 2020 Accepted: 8 July 2020

Published online: 22 July 2020

\section{References}

1. Calder PC. Marine omega-3 fatty acids and inflammatory processes: effects, mechanisms and clinical relevance. Biochim Biophys Acta. 2015; 1851(4):469-84

2. Fabian CJ, Kimler BF, Hursting SD. Omega-3 fatty acids for breast cancer prevention and survivorship. Breast Cancer Res. 2015;17:62.

3. Bendsen NT, Stender S, Szecsi PB, Pedersen SB, Basu S, Hellgren LI, et al. Effect of industrially produced trans fat on markers of systemic 
inflammation: evidence from a randomized trial in women. J Lipid Res. 2011;52(10):1821-8.

4. Teng K-T, Voon P-T, Cheng H-M, Nesaretnam K. Effects of partially hydrogenated, semi-saturated, and high oleate vegetable oils on inflammatory markers and lipids. Lipids. 2010;45(5):385-92.

5. Baer DJ, Judd JT, Clevidence BA, Tracy RP. Dietary fatty acids affect plasma markers of inflammation in healthy men fed controlled diets: a randomized crossover study. Am J Clin Nutr. 2004;79(6):969-73.

6. Han SN, Leka LS, Lichtenstein AH, Ausman LM, Schaefer EJ, Meydani SN. Effect of hydrogenated and saturated, relative to polyunsaturated, fat on immune and inflammatory responses of adults with moderate hypercholesterolemia. J Lipid Res. 2002;43(3):445-52.

7. Currie E, Schulze A, Zechner R, Walther TC, Farese RV. Cellular fatty acid metabolism and cancer. Cell Metab. 2013;18(2):153-61.

8. Medes G, Thomas A, Weinhouse S. Metabolism of neoplastic tissue. IV. A study of lipid synthesis in neoplastic tissue slices in vitro. Cancer Res. 1953; 13(1):27-9.

9. Bassett JK, Hodge AM, English DR, Maclnnis RJ, Giles GG. Plasma phospholipids fatty acids, dietary fatty acids, and breast cancer risk. Cancer Causes Control. 2016;27(6):759-73.

10. Pouchieu $C$, Chajès V, Laporte F, Kesse-Guyot E, Galan P, Hercberg $S$, et al. Prospective associations between plasma saturated, monounsaturated and polyunsaturated fatty acids and overall and breast cancer risk - modulation by antioxidants: a nested case-control study. PLoS One. 2014;9(2):e90442.

11. Takata Y, King IB, Neuhouser ML, Schaffer S, Barnett M, Thornquist M, et al. Association of serum phospholipid fatty acids with breast cancer risk among postmenopausal cigarette smokers. Cancer Causes Control. 2009; 20(4):497-504.

12. Chajès V, Thiébaut ACM, Rotival M, Gauthier E, Maillard V, Boutron-Ruault M$C$, et al. Association between serum trans-monounsaturated fatty acids and breast cancer risk in the E3N-EPIC study. Am J Epidemiol. 2008;167(11): 1312-20.

13. Rissanen $H$, Knekt $P$, Järvinen $R$, Salminen I, Hakulinen T. Serum fatty acids and breast cancer incidence. Nutr Cancer. 2003:45(2):168-75.

14. Saadatian-Elahi M, Toniolo P, Ferrari P, Goudable J, Akhmedkhanov A, Zeleniuch-Jacquotte A, et al. Serum fatty acids and risk of breast cancer in a nested case-control study of the New York University Women's Health Study. Cancer Epidemiol Biomark Prev. 2002;11(11):1353-60.

15. Chajès V, Hultén K, Van Kappel AL, Winkvist A, Kaaks R, Hallmans G, et al. Fatty-acid composition in serum phospholipids and risk of breast cancer: an incident case-control study in Sweden. Int J Cancer. 1999;83(5):585-90.

16. Vatten $L$, Bjerve KS, Andersen A, Jellum E. Polyunsaturated fatty acids in serum phospholipids and risk of breast cancer: a case-control study from the Janus serum bank in Norway. Eur J Cancer. 1993;29A(4):532-8.

17. Hirko KA, Chai B, Spiegelman D, Campos H, Farvid MS, Hankinson SE, et al. Erythrocyte membrane fatty acids and breast cancer risk: a prospective analysis in the nurses' health study II. Int J Cancer. 2018;142(6):1116-29.

18. Shannon J, King IB, Moshofsky R, Lampe JW, Gao DL, Ray RM, et al. Erythrocyte fatty acids and breast cancer risk: a case-control study in Shanghai, China. Am J Clin Nutr. 2007;85(4):1090-7.

19. Kuriki K, Hirose K, Wakai K, Matsuo K, Ito H, Suzuki T, et al. Breast cancer risk and erythrocyte compositions of $\mathrm{n}-3$ highly unsaturated fatty acids in Japanese. Int J Cancer. 2007:121(2):377-85.

20. Wirfält E, Vessby B, Mattisson I, Gullberg B, Olsson H, Berglund G. No relations between breast cancer risk and fatty acids of erythrocyte membranes in postmenopausal women of the Malmö Diet Cancer cohort (Sweden). Eur J Clin Nutr. 2004;58(5):761-70.

21. Pala V, Krogh V, Muti P, Chajès V, Riboli E, Micheli A, et al. Erythrocyte membrane fatty acids and subsequent breast cancer: a prospective Italian study. J Natl Cancer Inst. 2001;93(14):1088-95.

22. Zaridze DG, Chevchenko VE, Levtshuk AA, Lifanova YE, Maximovitch DM. Fatty acid composition of phospholipids in erythrocyte membranes and risk of breast cancer. Int J Cancer. 1990;45(5):807-10.

23. Arab L. Biomarkers of fat and fatty acid intake. J Nutr. 2003;133 Suppl 3(3): 925S-932S.

24. Rogero MM, Calder PC. Obesity, inflammation, toll-like receptor 4 and fatty acids. Nutrients. 2018 30;10(4).

25. Buck MD, O'Sullivan D, Pearce EL. T cell metabolism drives immunity. J Exp Med. 2015;212(9):1345-60.

26. Lochner M, Berod L, Sparwasser T. Fatty acid metabolism in the regulation of T cell function. Trends Immunol. 2015;36(2):81-91.
27. Binnewies M, Roberts EW, Kersten K, Chan V, Fearon DF, Merad M, et al. Understanding the tumor immune microenvironment (TIME) for effective therapy. Nat Med. 2018;24(5):541-50.

28. Mao Y, Qu Q, Chen X, Huang O, Wu J, Shen K. The prognostic value of tumor-infiltrating lymphocytes in breast cancer: a systematic review and meta-analysis. PLoS One. 2016;11(4):e0152500.

29. Stanton SE, Disis ML. Clinical significance of tumor-infiltrating lymphocytes in breast cancer. J Immunother Cancer. 2016;4:59.

30. Lau SK, Chu PG, Weiss LM. CD163: a specific marker of macrophages in paraffin-embedded tissue samples. Am J Clin Pathol. 2004;122(5):794-801.

31. Shen M, Wang J, Ren X. New insights into tumor-infiltrating B lymphocytes in breast cancer: clinical impacts and regulatory mechanisms. Front Immunol. 2018;9:470.

32. Esbona K, Yi Y, Saha S, Yu M, Van Doorn RR, Conklin MW, et al. The presence of cyclooxygenase 2, tumor-associated macrophages, and collagen alignment as prognostic markers for invasive breast carcinoma patients. Am J Pathol. 2018;188(3):559-73.

33. Koumarianou A, Christodoulou MI, Vaslamatzis M, Xiros N, Panteleon V, Themeli I, et al. Incidence and localization of tumor-infiltrating CD163+ macrophages and T-cells in early breast cancer patients. JCO. 2014;32(15_ suppl):11084-11084.

34. Medrek C, Pontén F, Jirström K, Leandersson K. The presence of tumor associated macrophages in tumor stroma as a prognostic marker for breast cancer patients. BMC Cancer. 2012;12:306.

35. Xu F, Li M, Zhang C, Cui J, Liu J, Li J, et al. Clinicopathological and prognostic significance of COX-2 immunohistochemical expression in breast cancer: a meta-analysis. Oncotarget. 2016;8(4):6003-12.

36. Menendez JA, Lupu R. Fatty acid synthase and the lipogenic phenotype in cancer pathogenesis. Nat Rev Cancer. 2007;7(10):763-77.

37. Tworoger SS, Sluss P, Hankinson SE. Association between plasma prolactin concentrations and risk of breast cancer among predominately premenopausal women. Cancer Res. 2006;66(4):2476.

38. Fortner RT, Eliassen AH, Spiegelman D, Willett WC, Barbieri RL, Hankinson SE. Premenopausal endogenous steroid hormones and breast cancer risk: results from the Nurses' Health Study II. Breast Cancer Res. 2013;15(2):R19.

39. Eliassen AH, Missmer SA, Tworoger SS, Spiegelman D, Barbieri RL, Dowsett $M$, et al. Endogenous steroid hormone concentrations and risk of breast cancer among premenopausal women. J Natl Cancer Inst. 2006;98(19):140615.

40. Sisti JS, Collins LC, Beck AH, Tamimi RM, Rosner BA, Eliassen AH. Reproductive risk factors in relation to molecular subtypes of breast cancer: results from the nurses' health studies. Int J Cancer. 2016;138(10):2346-56.

41. Tamimi RM, Baer HJ, Marotti J, Galan M, Galaburda L, Fu Y, et al. Comparison of molecular phenotypes of ductal carcinoma in situ and invasive breast cancer. Breast Cancer Res. 2008;10(4):R67.

42. Salgado R, Denkert C, Demaria S, Sirtaine N, Klauschen F, Pruneri G, et al. The evaluation of tumor-infiltrating lymphocytes (TILS) in breast cancer: recommendations by an International TILs Working Group 2014. Ann Oncol. 2015:26(2):259-71.

43. Fornetti J, Jindal S, Middleton KA, Borges VF, Schedin P. Physiological COX-2 expression in breast epithelium associates with COX-2 levels in ductal carcinoma in situ and invasive breast cancer in young women. Am J Pathol. 2014;184(4):1219-29.

44. Holmes MD, Chen WY, Schnitt SJ, Collins L, Colditz GA, Hankinson SE, et al. COX-2 expression predicts worse breast cancer prognosis and does not modify the association with aspirin. Breast Cancer Res Treat. 2011;130(2):657-62.

45. Ristimäki A, Sivula A, Lundin J, Lundin M, Salminen T, Haglund C, et al. Prognostic significance of elevated cyclooxygenase-2 expression in breast cancer. Cancer Res. 2002;62(3):632-5.

46. Urban J, Kuźbicki Ł, Szatkowski G, Stanek-Widera A, Lange D, Chwirot BW. Stromal, rather than epithelial cyclooxygenase-2 (COX-2) expression is associated with overall survival of breast cancer patients. BMC Cancer. 2014; $14: 732$.

47. Seo AN, Lee HJ, Kim EJ, Kim HJ, Jang MH, Lee HE, et al. Tumour-infiltrating CD8+ lymphocytes as an independent predictive factor for pathological complete response to primary systemic therapy in breast cancer. Br J Cancer. 2013;109(10):2705-13.

48. Baylin A, Kim MK, Donovan-Palmer A, Siles X, Dougherty L, Tocco P, et al. Fasting whole blood as a biomarker of essential fatty acid intake in epidemiologic studies: comparison with adipose tissue and plasma. Am J Epidemiol. 2005;162(4):373-81. 
49. Yang B, Ren X-L, Fu Y-Q, Gao J-L, Li D. Ratio of n-3/n-6 PUFAs and risk of breast cancer: a meta-analysis of 274135 adult females from 11 independent prospective studies. BMC Cancer. 2014;14:105.

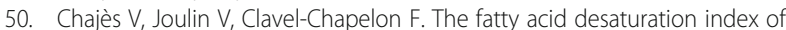
blood lipids, as a biomarker of hepatic stearoyl-CoA desaturase expression, is a predictive factor of breast cancer risk. Curr Opin Lipidol. 2011;22(1):6-10.

51. Patel PS, Sharp SJ, Jansen E, Luben RN, Khaw K-T, Wareham NJ, et al. Fatty acids measured in plasma and erythrocyte-membrane phospholipids and derived by food-frequency questionnaire and the risk of new-onset type 2 diabetes: a pilot study in the European Prospective Investigation into Cancer and Nutrition (EPIC)-Norfolk cohort. Am J Clin Nutr. 2010;92(5):1214-22.

52. Wang M, Spiegelman D, Kuchiba A, Lochhead P, Kim S, Chan AT, et al. Statistical methods for studying disease subtype heterogeneity. Stat Med. 2016;35(5):782-800.

53. Pearl J. Causal diagrams for empirical research. Biometrika. 1995;82(4):669-88.

54. Durrleman S, Simon R. Flexible regression models with cubic splines. Stat Med. 1989;8(5):551-61.

55. Zheng J-S, Hu X-J, Zhao Y-M, Yang J, Li D. Intake of fish and marine n-3 polyunsaturated fatty acids and risk of breast cancer: meta-analysis of data from 21 independent prospective cohort studies. BMJ. 2013;346:f3706.

56. Manson JE, Cook NR, Lee I-M, Christen W, Bassuk SS, Mora S, et al. Marine n3 fatty acids and prevention of cardiovascular disease and cancer. N Engl J Med. 2019 03;380(1):23-32.

57. Weylandt KH, Chiu C-Y, Gomolka B, Waechter SF, Wiedenmann B. Omega-3 fatty acids and their lipid mediators: towards an understanding of resolvin and protectin formation. Prostaglandins Other Lipid Mediat. 2012;97(3-4): $73-82$.

58. Turk HF, Chapkin RS. Membrane lipid raft organization is uniquely modified by $n-3$ polyunsaturated fatty acids. Prostaglandins Leukot Essent Fatty Acids. 2013;88(1):43-7.

59. Vega-López S, Matthan NR, Ausman LM, Ai M, Otokozawa S, Schaefer EJ, et al. Substitution of vegetable oil for a partially-hydrogenated fat favorably alters cardiovascular disease risk factors in moderately hypercholesterolemic postmenopausal women. Atherosclerosis. 2009;207(1):208-12.

60. Motard-Bélanger A, Charest A, Grenier G, Paquin P, Chouinard Y, Lemieux S, et al. Study of the effect of trans fatty acids from ruminants on blood lipids and other risk factors for cardiovascular disease. Am J Clin Nutr. 2008;87(3): 593-9.

61. Tholstrup T, Raff M, Basu S, Nonboe P, Sejrsen K, Straarup EM. Effects of butter high in ruminant trans and monounsaturated fatty acids on lipoproteins, incorporation of fatty acids into lipid classes, plasma C-reactive protein, oxidative stress, hemostatic variables, and insulin in healthy young men. Am J Clin Nutr. 2006;83(2):237-43.

62. Lichtenstein AH, Erkkilä AT, Lamarche B, Schwab US, Jalbert SM, Ausman LM. Influence of hydrogenated fat and butter on CVD risk factors: remnantlike particles, glucose and insulin, blood pressure and C-reactive protein. Atherosclerosis. 2003:171(1):97-107.

63. Bloomer SA, Wellen KE, Henderson GC. Sexual dimorphism in the hepatic protein response to a moderate trans fat diet in senescence-accelerated mice. Lipids Health Dis. 2017;16(1):243.

64. Cassagno N, Palos-Pinto A, Costet $P$, Breilh D, Darmon M, Bérard AM. Low amounts of trans 18:1 fatty acids elevate plasma triacylglycerols but not cholesterol and alter the cellular defence to oxidative stress in mice. $\mathrm{Br} \mathrm{J}$ Nutr. 2005;94(3):346-52.

65. Shimano H. Sterol regulatory element-binding proteins (SREBPs): transcriptional regulators of lipid synthetic genes. Prog Lipid Res. 2001;40(6):439-52.

66. Alo' PL, Visca P, Marci A, Mangoni A, Botti C, Di Tondo U. Expression of fatty acid synthase (FAS) as a predictor of recurrence in stage I breast carcinoma patients. Cancer. 1996;77(3):474-482.

67. Tamimi RM, Colditz GA, Hazra A, Baer HJ, Hankinson SE, Rosner B, et al. Traditional breast cancer risk factors in relation to molecular subtypes of breast cancer. Breast Cancer Res Treat. 2012;131(1):159-67.

68. Monaco ME. Fatty acid metabolism in breast cancer subtypes. Oncotarget. 2017:8(17):29487-500.

69. Giró-Perafita A, Sarrats A, Pérez-Bueno F, Oliveras G, Buxó M, Brunet J, et al Fatty acid synthase expression and its association with clinicohistopathological features in triple-negative breast cancer. Oncotarget. 2017; 8(43):74391-405.

70. Nagalla S, Chou JW, Willingham MC, Ruiz J, Vaughn JP, Dubey P, et al. Interactions between immunity, proliferation and molecular subtype in breast cancer prognosis. Genome Biol. 2013;14(4):R34.
71. Hammerl D, Smid M, Timmermans AM, Sleijfer S, Martens JWM, Debets R. Breast cancer genomics and immuno-oncological markers to guide immune therapies. Semin Cancer Biol. 2018;52(Pt 2):178-88.

72. Kotsopoulos J, Tworoger SS, Campos H, Chung F-L, Clevenger CV, Franke A, et al. Reproducibility of plasma and urine biomarkers among premenopausal and postmenopausal women from the Nurses' Health Studies. Cancer Epidemiol Biomark Prev. 2010;19(4):938-46.

\section{Publisher's Note}

Springer Nature remains neutral with regard to jurisdictional claims in published maps and institutional affiliations.
Ready to submit your research? Choose BMC and benefit from:

- fast, convenient online submission

- thorough peer review by experienced researchers in your field

- rapid publication on acceptance

- support for research data, including large and complex data types

- gold Open Access which fosters wider collaboration and increased citations

- maximum visibility for your research: over $100 \mathrm{M}$ website views per year

At BMC, research is always in progress.

Learn more biomedcentral.com/submissions 